ARTICLE

Received 9 Mar 2015 | Accepted 28 Apr 2015 | Published 15 Jun 2015

DOI: $10.1038 /$ ncomms 8340

OPEN

\title{
1,3,2,5-Diazadiborinine featuring nucleophilic and electrophilic boron centres
}

Di Wu${ }^{1}$, Lingbing Kong ${ }^{1}$, Yongxin $\mathrm{Li}^{2}$, Rakesh Ganguly ${ }^{2} \&$ Rei Kinjo ${ }^{1}$

The seminal discovery in 1865 by Kekulé that benzene nucleus exists with cyclic skeleton is considered to be the beginning of aromatic chemistry. Since then, a myriad of cyclic molecules displaying aromatic property have been synthesized. Meanwhile, borazine $\left(B_{3} \mathrm{~N}_{3} \mathrm{H}_{6}\right)$, despite the isostructural and isoelectronic relationships with benzene, exhibits little aromaticity. Herein, we report the synthesis of a 1,3,2,5-diazadiborinine $\left(B_{2} C_{2} N_{2} R_{6}\right)$ derivative, a hybrid inorganic/organic benzene, and we present experimental and computational evidence for its aromaticity. In marked contrast to the reactivity of benzene, borazine, and even azaborinines previously reported, 1,3,2,5-diazadiborinine readily forms the adducts with methyl trifluoromethanesulfonate and phenylacetylene without any catalysts. Moreover, 1,3,2,5-diazadiborine activates carbon dioxide giving rise to a bicycle[2,2,2] product, and the binding process was found to be reversible. These results, thus, demonstrate that 1,3,2,5diazadiborinine features both nucleophilic and electrophilic boron centres, with a formal $\mathrm{B}(+\mathrm{I}) / \mathrm{B}(+\mathrm{III})$ mixed valence system, in the aromatic six-membered $\mathrm{B}_{2} \mathrm{C}_{2} \mathrm{~N}_{2}$ ring.

\footnotetext{
${ }^{1}$ Division of Chemistry and Biological Chemistry, Nanyang Technological University, 21 Nanyang Link, 637371 Singapore, Singapore. ${ }^{2}$ NTU-CBC Crystallography Facility, Nanyang Technological University, 21 Nanyang Link, 637371 Singapore, Singapore. Correspondence and requests for materials should be addressed to R.K. (email: rkinjo@ntu.edu.sg).
} 
$\mathrm{T}$ he concept of aromaticity has been of paramount importance in myriad fields of chemistry since the discovery in 1865 that benzene nucleus is cyclic ${ }^{1}$. Almost a century after the first identification of benzene by Faraday ${ }^{2}$, borazine $\left(\mathrm{B}_{3} \mathrm{~N}_{3} \mathrm{H}_{6}\right)$, also referred as inorganic benzene, was prepared $^{3}$. Despite the isoelectronic and isosterism relationships between the $\mathrm{C}=\mathrm{C}$ and $\mathrm{B}-\mathrm{N}$ units, however, $\mathrm{B}_{3} \mathrm{~N}_{3} \mathrm{H}_{6}$ displays a different electronic property from that of benzene $e^{4,5}$, which is due to polarization of the $\mathrm{B}-\mathrm{N}$ units arising from the variation of electronegativity between boron and nitrogen atoms. Thus, introduction of $\mathrm{B}-\mathrm{N}$ units into the aromatic skeleton of isoelectronic organic counterparts leads to unique electronic structures, which indicate the potential to expand the diversity of aromatic molecules ${ }^{6-8}$.

In 1958, Dewar and co-workers first reported the preparation of a polycyclic azaborinine ${ }^{9}$. Since then, the synthesis and full characterization of various mono-cyclic and ring-fused polycyclic azaborinine $\left(\mathrm{BNC}_{4}\right)$ derivatives, involving 1,2-azborinines, 1,3 -azaborinines and 1,4-azaborinines, have been achieved ${ }^{10}$. Meanwhile, only a few diazadiborinine $\left(\mathrm{B}_{2} \mathrm{~N}_{2} \mathrm{C}_{2}\right)$ derivatives have been structurally characterized so far ${ }^{11,12}$. Thermal stability as well as aromatic nature of both azaborinine and diazadiborinine more closely resembles those of benzene than $\mathrm{B}_{3} \mathrm{~N}_{3} \mathrm{H}_{6}$. Nevertheless, except for $\eta^{6}$-complexation with a chromium and ruthenium metals, the reactivities of the boron centre in these compounds are mainly associated with nucleophilic substitutions, which is in contrast to the reactivity of benzene where electrophilic substitution is archetypal. Thus, the boron in these compounds only acts as a classical electron pair acceptor. Recently, Bertrand and our groups ${ }^{13-16}$ independently developed neutral tricoordinate organoboron species possessing a nucleophilic boron centre, which is formally in the + I oxidation state. We were interested in incorporating a nucleophilic boron centre into diazadiborinine skeleton because the resulting $\mathrm{B}_{2} \mathrm{~N}_{2} \mathrm{C}_{2}$ ring would involve both nucleophilic and electrophilic boron centres, which can be formally considered as a $\mathrm{B}(+\mathrm{I}) / \mathrm{B}(+\mathrm{III})$ mixed valence system ${ }^{17-20}$. Among extant nonmetal-based mixed valence compounds ${ }^{21,22}$, it has been reported that charge-neutral mixed valence system especially with closedshell form, namely donor-acceptor system, exhibit high stability $^{23}$. We reasoned that incorporation of the mixed valence system into aromatic ring would effectively lead to charge delocalization as found in mixed valence bimetallic compounds categorized into class II and $\mathrm{III}^{24,25}$. Meanwhile, preparation of such molecules with p-block heteroatoms is highly challenging owing to the limitation of synthetic approach for their low oxidation state. Indeed, for heterobenzene featuring mixed valence systems of the p-block inorganic elements, only the valence isomers of hexasilabenzene ${ }^{26}$ and tetraphosphabenzene ${ }^{27}$ are known. No relevant species involving mixed valence system of boron atoms have been described thus far.

Herein, we report the synthesis, single-crystal X-ray diffraction analysis and computational studies of 1,3,2,5-diazadiborinine 4 . We show that this compound possesses both nucleophilic and electrophilic boron centres with a formal $\mathrm{B}(+\mathrm{I}) / \mathrm{B}(+\mathrm{III})$ mixed valence system in the aromatic six-membered ring.

\section{Results}

Synthesis and characterization of 4 . Oxazolinyl groups were introduced into a boron atom by treatment of two equivalents of 2-lithio-4,4'-dimethyl-2-oxazolide $\mathbf{1}$ with dichlorophenylborane (Fig. 1). Without further purification of the crude product 2 , a subsequent reaction with one equivalent of dichlorophenylborane in toluene afforded a 2,5-dichloro-1,3,2,5-diazadiborinine derivative 3 (29\% yield), which was fully characterized by standard spectroscopic methods, including a single-crystal X-ray diffraction study. Treatment of $\mathbf{3}$ with excess amounts of potassium graphite $\left(\mathrm{KC}_{8}\right)$ in toluene cleanly proceeded, and after workup 1,3,2,5-diazadiborinine derivative $\mathbf{4}$ was isolated as a white powder in $32 \%$ yield. In the ${ }^{11} \mathrm{~B}$ nuclear magnetic resonance (NMR) spectrum of $\mathbf{4}$, a sharp signal for the boron atom between two carbon atoms appeared at $\delta=7.3$ parts per million (p.p.m.) and a broad peak for the boron atom between two nitrogen atoms was observed at $\delta=24.9$ p.p.m. Both signals shifted downfield compared with those of the precursor $\mathbf{3}(\delta=-11.4$ and 3.5 p.p.m.). Compound 4 is thermally stable both in the solid state and in solutions, and it melts at $133^{\circ} \mathrm{C}$ without decomposition.

Single crystals of 4 suitable for X-ray diffractometry were obtained by recrystallization from a benzene solution at room temperature, and crystallographic analysis revealed that the six-membered $\mathrm{B}_{2} \mathrm{C}_{2} \mathrm{~N}_{2}$ ring of $\mathbf{4}$ is nearly planar (Fig. 2a). Two boron atoms display trigonal-planar geometry (the sum of bond angles: $\mathrm{B} 1=359.96^{\circ}$ and $\mathrm{B} 2=359.93^{\circ}$ ), which are characteristic for $s p^{2}$ hybridization. Phenyl ring at $\mathrm{B} 2$ and the $\mathrm{B}_{2} \mathrm{C}_{2} \mathrm{~N}_{2}$ six-membered ring are nearly perpendicular to each other with the twist angle of $89.1^{\circ}$, whereas phenyl group at $\mathrm{B} 1$ and the $\mathrm{B}_{2} \mathrm{C}_{2} \mathrm{~N}_{2}$ skeleton are slightly twisted by $11.9^{\circ}$. The $\mathrm{B} 1-\mathrm{C} 5$ (1.483(3) $\AA$ ) and $\mathrm{B} 2-\mathrm{N} 1(1.443(3) \AA)$ distances are significantly

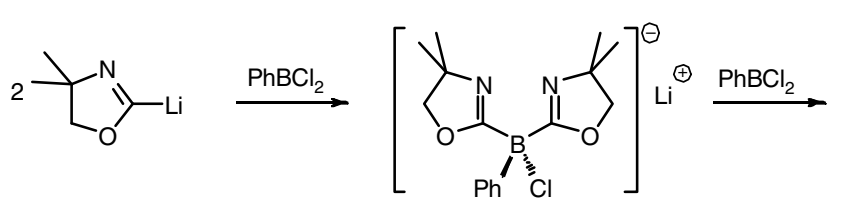

1

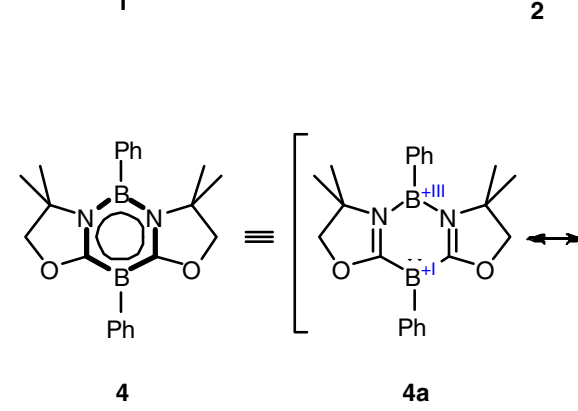

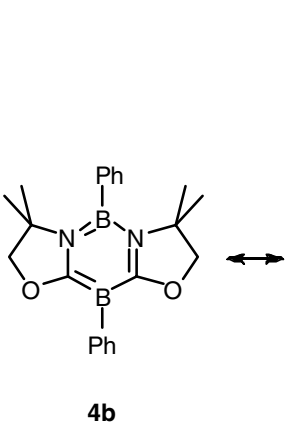<smiles></smiles><smiles>CC(C)(C)[Mg]</smiles><smiles>CC1(C)CCOC2=[PH](Pc3ccccc3)B3OCC(C)(C)N3B21</smiles>

4c

Figure 1 | Preparation of 1,3,2,4-diazadiborinine 4. $4 a-c$ present the resonance forms. 


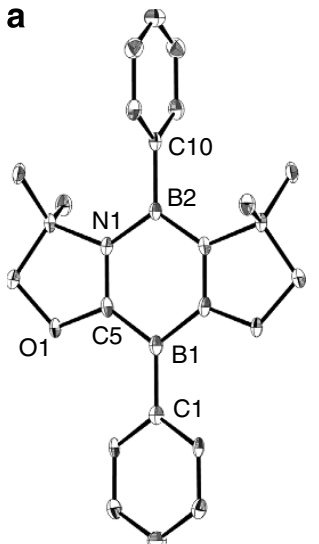

b

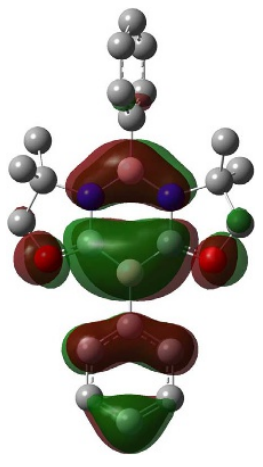

C

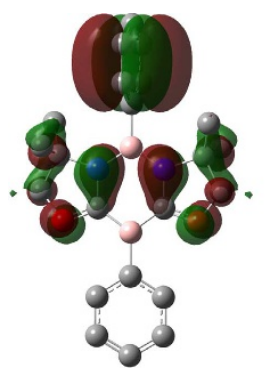

d

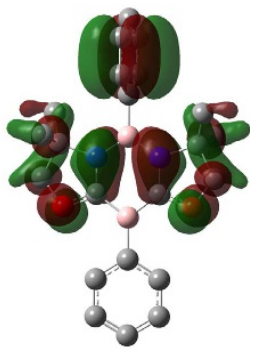

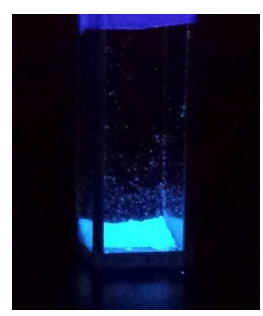

Figure 2 | Structural characterization and fluorescence property. (a) Solid state structure of $\mathbf{4}$. Thermal ellipsoids are set at the $30 \%$ probability level. Hydrogen atoms are omitted for clarity. (b) Plot of the HOMO of 4. (c) Plots of the HOMO-4 (left) and HOMO-5 (right) of 4. Calculated at the B3LYP/6-311 $+G(d, p)$ level of theory. Hydrogen atoms are omitted for clarity. (d) Photographic image of fluorescence emission in the solid state of $\mathbf{4}$ under irradiation of a ultraviolet lamp.

shorter than those (1.575(5)-1.589(5) $\AA$ and 1.573(4)-1.563(4) $\AA$ ) in 3 , and lie between typical single and double-bond distances of boron-carbon and boron-nitrogen bonds, respectively. In contrast, the N1-C5 distance of 1.374(3) $\AA$ is longer than that $(1.287(4)-1.292(4) \AA)$ in 3 . These structural features suggest the delocalization of $6 \pi$-electrons over the six-membered $\mathrm{B}_{2} \mathrm{C}_{2} \mathrm{~N}_{2}$ ring in 4 , which can be represented by the average of the several canonical forms including $\mathbf{4 a - c}$.

Computational studies. To gain further insight into the electronic features of $\mathbf{4}$, quantum chemical density functional theory calculation involving geometry optimization, natural bond orbital analysis and natural population analysis were performed at the B3LYP/6-311G + $(\mathrm{d}, \mathrm{p})$ level of theory. The optimized geometry of $\mathbf{4}$ was in good agreement with the structural parameters determined experimentally. Natural bond orbital analysis gave Wiberg bond index value for the boron-nitrogen bonds ( 0.96 for B2-N1). Meanwhile, Wiberg bond index values lager than 1 for the $\mathrm{B} 1-\mathrm{C} 5$ bonds (1.21) and the $\mathrm{C} 5-\mathrm{N} 1$ bonds (1.14) were obtained, thus suggesting the partial double-bond character of these bonds. Indeed, the HOMO of 4 displays a $\pi$-system over the six-membered $\mathrm{B}_{2} \mathrm{C}_{2} \mathrm{~N}_{2}$ ring featuring a node between the NBN and $\mathrm{CBC} \pi$-unites, which exhibits anti-bonding conjugation with the $\pi$-orbital in the phenyl ring bounded to the $\mathrm{B} 1$ atom (Fig. $2 \mathrm{~b}$ ). $\pi$-Bonding interactions between the $\mathrm{C} 5$ atom and the $\mathrm{N} 1$ atom were confirmed in HOMO-4 and HOMO-5 (Fig. 2c). In the ultraviolet-visible absorption spectrum of 4 in a tetrahydrofuran (THF) solution, an absorption band was observed at wavelength ( $\lambda$ ) of $275 \mathrm{~nm}$, which is comparable to that $(\lambda=277 \mathrm{~nm})$ of para-terphenyl $\left(\mathrm{PhC}_{6} \mathrm{H}_{4} \mathrm{Ph}\right)$ bearing all-carbon aromatic skeleton isoelectronic with $\mathbf{4}$ (ref. 28). Interestingly, we observed that $\mathbf{4}$ has little fluorescence in any solution, whereas it displays distinct light blue-fluorescence emission in the solid state under a ultraviolet lamp (Fig. 2d; refs 29,30). The broad emission peak of 4 at $(\lambda=423 \mathrm{~nm})$ was bathochromically shifted by $80 \mathrm{~nm}$ in comparison with para-terphenyl $(\lambda=343 \mathrm{~nm})$.

To evaluate the aromatic property of $\mathbf{4}$, the nucleus-independent chemical-shift values NICS(0) and NICS(1) were calculated for parent 1,3,2,5-diazadiborinine $4^{\prime}$, benzene $\left(\mathrm{C}_{6} \mathrm{H}_{6}\right), 1,2$-azaborine, 1,3-azaborine and $\mathrm{B}_{3} \mathrm{~N}_{3} \mathrm{H}_{6}$ (Fig. 3). The NICS values for $4^{\prime}$ are less negative than those of benzene and 1,3-azaborine, but comparable to those of 1,2-azaborine, and more negative with respect to those of $\mathrm{B}_{3} \mathrm{~N}_{3} \mathrm{H}_{6}$. Thus, it is predicted that 1,3,2,5-diazadiborinine features aromaticity, which seems smaller than those of benzene

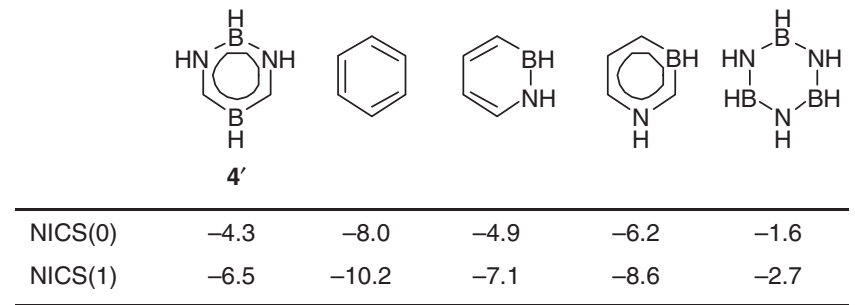

Figure 3 | Results of density functional theory calculations. Calculated $\operatorname{NICS}(0)$ and $\operatorname{NICS}(1)$ values for $\mathbf{4}^{\prime}$, benzene, 1,2-azaborine, 1,3-azaborine and $\mathrm{B}_{3} \mathrm{~N}_{3} \mathrm{H}_{6}$. Calculated at the B3LYP/6-311 $+\mathrm{G}(\mathrm{d}, \mathrm{p})$ level of theory.

and 1,3-azaborine, but greater than that of $\mathrm{B}_{3} \mathrm{~N}_{3} \mathrm{H}_{6}$. To estimate the resonance stabilization energy (RSE) of the parent $1,3,2$, 5-diazadiborinine $\mathbf{4}^{\prime}$, we performed further computational analysis. The RSE value of $4^{\prime}$ is $\sim 22.4 \mathrm{kcal} \mathrm{mol}^{-1}$ less than that of benzene $\left(34.1 \mathrm{kcal} \mathrm{mol}^{-1}\right)$, which is smaller than those of 1,3azaborinine $\left(\mathrm{RSE}=29 \mathrm{kcal} \mathrm{mol}^{-1}\right)($ ref. 31) and 1,2-azaborinine $\left(\mathrm{RSE}=21 \mathrm{kcal} \mathrm{mol}^{-1}\right)($ ref. 32).

Reactivity. To investigate the reactivity of $\mathbf{4}$, we performed its reaction with methyl trifluoromethanesulfonate (MeOTf). A stoichiometric amount of MeOTf was added to an acetonitrile solution of $\mathbf{4}$ at ambient temperature. After removing the solvent under vacuum, $\mathbf{5}$ was obtained in $75 \%$ yield (Fig. 4a). An $\mathrm{X}$-ray diffraction study confirmed that methyl group is attached to the boron atom between two carbons in the $\mathrm{B}_{2} \mathrm{C}_{2} \mathrm{~N}_{2}$ ring, whereas an oxygen atom of the triflate is bounded to the boron atom between two nitrogen atoms (Fig. 4b, left). This result, thus, demonstrates that 4 features both nucleophilic and electrophilic boron centres, thereby supporting the electronic property of the resonance structure $4 a$ (Fig. 1). The formal oxidation states of the $\mathrm{B} 1$ and the $\mathrm{B} 2$ atoms in $\mathbf{4 a}$ are $+\mathrm{I}$ and + III, respectively. Thus, $\mathbf{4}$ presents a donor-acceptor mixed valence system.

Reactivity of neutral boron nucleophiles has seldom been explored thus far ${ }^{13-16}$. Based on the behaviours of 4 with MeOTf, we postulated that $\mathbf{4}$ would act as a frustrated Lewis pair, since it possesses both Lewis basic and acidic boron centres $^{33-37}$. To bear out the hypothesis, we next investigated the reactivity of $\mathbf{4}$ towards non-activated alkynes. In a J-Young NMR tube, a stoichiometric amount of phenylacetylene was added to a $\mathrm{C}_{6} \mathrm{D}_{6}$ solution of 4 , and reaction was monitored by NMR 


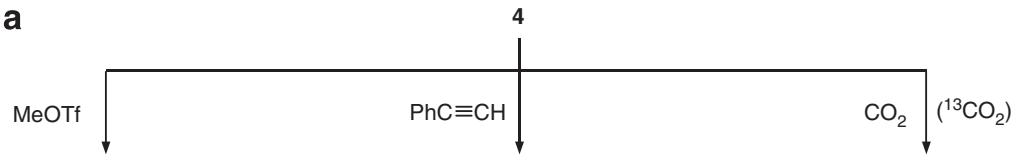

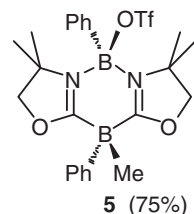

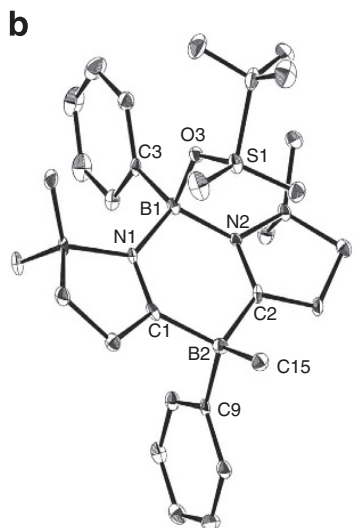

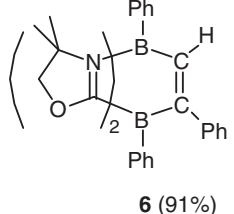

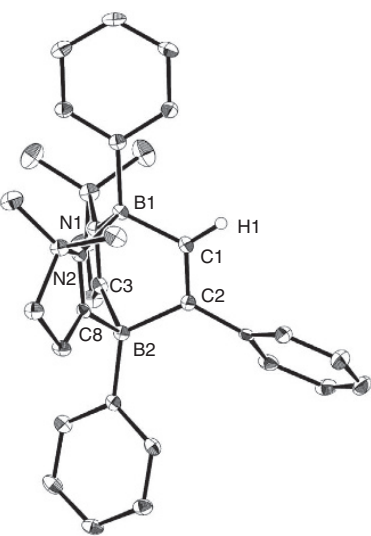

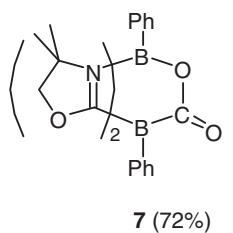

$\left(7-{ }^{13} \mathrm{C}\right)$

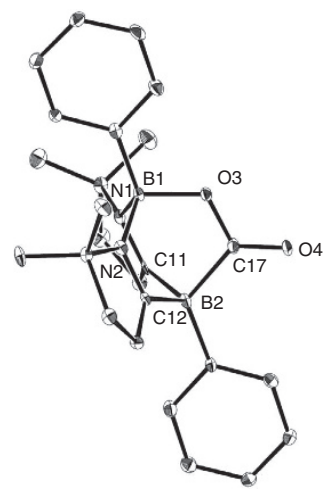

Figure 4 | Reactivity of 4. (a) Reactions of 4 with MeOTf, $\mathrm{PhC} \equiv \mathrm{CH}$ and $\mathrm{CO}_{2}\left({ }^{13} \mathrm{CO}_{2}\right)$. (b) Solid state structures of 5 (left), 6 (middle) and 7 (right). Thermal ellipsoids are set at the 30\% probability level. Hydrogen atoms except for $\mathrm{H} 1$ in $\mathbf{6}$ and solvent molecules are omitted for clarity.

spectroscopy. After $2 \mathrm{~h}$ at $70^{\circ} \mathrm{C}$, two new signals were detected at -13.6 and 0.1 p.p.m. in the ${ }^{{ }^{1}} \mathrm{~B}$ NMR spectrum. After workup, compound $\mathbf{6}$ was isolated as a white powder in $91 \%$ yield. The crystallographic study revealed the diazadiborabicycle[2.2.2] structure involving the $\mathrm{C}=\mathrm{N}$ double bonds (N1-C3: 1.299(4) $\AA$ and N2-C8: 1.299(3) $\AA$ ) (Fig. 4b, middle). Thus, 6 is a formal Diels-Alder product via a $[4+2]$ cyclo-addition between 4 and the carbon-carbon triple bond of phenylacetylene. It is noteworthy to mention that Diels-Alder addition of alkynes to aromatic hydrocarbons normally is restricted to highly reactive aromatic compounds and activated alkynes under harsh conditions ${ }^{38,39}$. Moreover, 6 can be viewed as an analogue of bicycle[2.2.2] octatriene, also termed barrelene, which is inferred to be one of the Möbius aromatic compounds 39 .

Next, we examined the carbon dioxide $\left(\mathrm{CO}_{2}\right)$ activation with 4 (ref. 40). $\mathrm{CO}_{2}$ gas was introduced into a benzene solution of 4 at $1 \mathrm{bar}$, and the solution was heated at $70^{\circ} \mathrm{C}$. After $2 \mathrm{~h}$, a white precipitate was filtered and dried under vacuum to afford compound 7 in $72 \%$ yield. We also carried out a ${ }^{13} \mathrm{C}$-labelling study using ${ }^{13} \mathrm{CO}_{2}$, which produced $7-{ }^{13} \mathrm{C}$ (80\% yield). The ${ }^{13} \mathrm{C}$ NMR spectrum of ${ }^{7-}{ }^{13} \mathrm{C}$ displayed a broad resonance at 191.1 p.p.m. In the ${ }^{11} \mathrm{~B}$ NMR spectrum, a set of new peaks was observed at 3.1 p.p.m. as a broad singlet and -16.7 p.p.m. as a broad doublet $\left({ }_{\mathrm{B}-\mathrm{C}}=42.4 \mathrm{~Hz}\right)$, which is owing to the coupling with a ${ }^{13} \mathrm{C}$ carbon atom. These results indicate the presence of a bond between a boron and the carbon from $\mathrm{CO}_{2}$ in 7 , which was decisively confirmed by X-ray diffractometry (Fig. $4 \mathrm{~b}$, right). One of the $\mathrm{C}=\mathrm{O}$ double bonds of $\mathrm{CO}_{2}$ was cleaved and new $\mathrm{B}-\mathrm{C}$ and $\mathrm{B}-\mathrm{O}$ bonds are formed through 1,4 addition, which is contrast to the behaviour of benzene that reacts with $\mathrm{CO}_{2}$ to form benzoic acid only in the presence of Lewis acid catalysts ${ }^{41}$. We also found that the $\mathrm{CO}_{2}$ activation process by 4 was reversible. Thus, treatment of 7 at $90^{\circ} \mathrm{C}$ for $50 \mathrm{~min}$ reproduced 4 , quantitatively.

\section{Discussion}

One-hundred fifty years after the discovery of the cyclic structure of benzene, 1,3,2,5-diazadiborinine derivative 4 featuring a formal $\mathrm{B}(+\mathrm{I}) / \mathrm{B}(+\mathrm{III})$ mixed valence system has joined as a heteroanalogue into a class of $6 \pi$-Hückel aromatic molecules. In marked contrast to the chemical behaviour of benzene, $\mathrm{B}_{3} \mathrm{~N}_{3} \mathrm{H}_{6}$ or even other azaborinines, 4 exhibits unique optical property and reactivity like a boron-boron frustrated Lewis pair. Because the electronic property can be substantially modulated by varying the substituents on each boron atom, the isolation of this molecule paves the way for the discovery of new materials with useful photochemical properties. Moreover, the cooperative reactivity of the nucleophilic and electrophilic boron centres, and the reversible nature for activation of small molecules will be applicable to catalytic chemistry.

\section{Methods}

Materials. For details of spectroscopic analyses of compounds in this manuscript see Supplementary Figs 1-25. For details of density functional theory calculations, see Supplementary Fig. 26, Supplementary Tables 3-5 and Supplementary Methods. For details of the synthetic procedures, see Supplementary Methods. For details of X-ray analysis, see Supplementary Data 1-5, Supplementary Tables 1 and 2, and Supplementary Methods.

General synthetic procedures. All reactions were performed under an atmosphere of dry argon using standard Schlenk or dry box techniques; solvents were dried over Na metal, $\mathrm{K}$ metal or $\mathrm{CaH}_{2}$, and were distilled under nitrogen. Reagents were of analytical grade, obtained from commercial suppliers and were used without further purification. ${ }^{1} \mathrm{H},{ }^{13} \mathrm{C},{ }^{11} \mathrm{~B}$ and ${ }^{19} \mathrm{~F}$ NMR spectra were recorded on a Bruker AVIII $400 \mathrm{MHz}$ or Bruker Avance $500 \mathrm{MHz}$ AV500 spectrometers at $298 \mathrm{~K}$. Chemical shifts $(\delta)$ are given in p.p.m. Coupling constants $J$ are given in Hz. In the ${ }^{13} \mathrm{C}$ NMR spectra of compounds $3-7$, presumable owing to the coupling with boron atoms, signals for the carbon atoms directly bonding to boron atoms could not be observed. Electrospray ionization (ESI) mass spectra were obtained at the Mass Spectrometry Laboratory at the Division of Chemistry and Biological

Chemistry, Nanyang Technological University. Melting points were measured with OptiMelt (Stanford Research System). Fourier-transform infrared (FT-IR) spectra 
were recorded on a SHIMADZU IRPrestige-21 spectrometer using solid compound. Ultraviolet and fluorescence spectra were recorded on Cary 100 UV-Vis and SHIMADZU RF-5301PC spectrofluorophotometer, respectively.

Synthesis of 3. A hexane solution ( $1.6 \mathrm{M})$ of $n$-BuLi $(6.25 \mathrm{ml}, 10.00 \mathrm{mmol})$ was added dropwise into a THF solution (50 ml) of 4,4-dimethyl-2-oxazoline $(1.00 \mathrm{ml}$, $9.48 \mathrm{mmol}$ ) at $-78^{\circ} \mathrm{C}$. After stirring for $1 \mathrm{~h}$ at $-78^{\circ} \mathrm{C}$, dichlorophenylborane $(0.62 \mathrm{ml}, 4.72 \mathrm{mmol})$ was added into the solution. The reaction mixture was warmed to room temperature and stirred overnight. After the solvent was removed under vacuum, toluene $(60 \mathrm{ml})$ was added and salts were filtered off, which was used directly for next step without further purification. Dichlorophenylborane $(0.62 \mathrm{ml}, 4.72 \mathrm{mmol})$ was added dropwise into the solution at $-78^{\circ} \mathrm{C}$. The reaction mixture was left to stir for $1 \mathrm{~h}$ at $-78^{\circ} \mathrm{C}$, and slowly warmed to room temperature and stirred overnight. The solvent was removed under vacuum, and the solid residue was recrystallized from benzene to afford colourless crystals of $3(0.61 \mathrm{~g}$, $29 \%)$. Melting point (Mp): $207^{\circ} \mathrm{C} .{ }^{1} \mathrm{H}$ NMR $\left(400 \mathrm{MHz}, \mathrm{C}_{6} \mathrm{D}_{6}\right): \delta=0.52(\mathrm{~s}, 6 \mathrm{H})$, $1.21(\mathrm{~s}, 6 \mathrm{H}), 3.06(\mathrm{~d}, 2 \mathrm{H}, J=9.2 \mathrm{~Hz}), 3.13(\mathrm{~d}, 2 \mathrm{H}, J=8.8 \mathrm{~Hz}), 7.21-8.29(\mathrm{~m}, 10 \mathrm{H})$; ${ }^{13} \mathrm{C}$ NMR $\left(100 \mathrm{MHz}, \mathrm{C}_{6} \mathrm{D}_{6}\right): \delta=24.2,27.5,68.3,81.8,127.6,132.4,133.1,136.0$; DEPT-135 NMR $\left(100 \mathrm{MHz}, \mathrm{C}_{6} \mathrm{D}_{6}\right): \delta=24.2,27.5,127.6,128.0,128.3 .132 .4$, 133.1, 136.0. ${ }^{11} \mathrm{~B}$ NMR $\left(76.8 \mathrm{MHz}, \mathrm{C}_{6} \mathrm{D}_{6}\right): \delta=-11.4$ (s), 3.5 (s); HRMS (ESI): $\mathrm{m} / z$ calculated for $\mathrm{C}_{22} \mathrm{H}_{26} \mathrm{~B}_{2} \mathrm{~N}_{2} \mathrm{O}_{2} \mathrm{Cl}$ : $407.1869[(M)]^{+}$; found: 407.1866.

Synthesis of 4. Potassium graphite $(1.49 \mathrm{~g}, 11.04 \mathrm{mmol})$ was slowly added to a solution of $3(0.82 \mathrm{~g}, 1.84 \mathrm{mmol})$ in toluene $(50 \mathrm{ml})$ and stirred overnight at room temperature. After filtration, the solvent was concentrated to $5 \mathrm{ml}$ under vacuum. The solid residue was filtered off and washed with hexane $(15 \mathrm{ml})$, and then dried under vacuum to afford 4 as a white powder $(0.22 \mathrm{~g}, 32 \%)$. Mp: $133^{\circ} \mathrm{C} .{ }^{1} \mathrm{H}$ NMR $\left(400 \mathrm{MHz}, \mathrm{C}_{6} \mathrm{D}_{6}\right): \delta=0.79(\mathrm{~s}, 12 \mathrm{H}), 3.63(\mathrm{~s}, 4 \mathrm{H}), 7.09-8.84(\mathrm{~m}, 10 \mathrm{H}) ;{ }^{13} \mathrm{C} \mathrm{NMR}$ $\left(100 \mathrm{MHz}, \mathrm{C}_{6} \mathrm{D}_{6}\right): \delta=27.5,62.8,80.9,125.4,127.1,127.7,134.7,135.1 ; \mathrm{DEPT}-135$ $\operatorname{NMR}\left(100 \mathrm{MHz}, \mathrm{C}_{6} \mathrm{D}_{6}\right): \delta=27.5,125.4,127.1,127.7,128.4,134.7,135.1 ;{ }^{11} \mathrm{~B}$ NMR $\left(76.8 \mathrm{MHz}, \mathrm{C}_{6} \mathrm{D}_{6}\right): \delta=7.3(\mathrm{~s}), 24.9$ (s); Ultraviolet-visible (THF): $\lambda=275 \mathrm{~nm}$ ( $\varepsilon: 5,740$ ); HRMS (ESI): $m / z$ calculated for $\mathrm{C}_{22} \mathrm{H}_{27} \mathrm{~B}_{2} \mathrm{~N}_{2} \mathrm{O}_{2}: 373.2259[(M+H)]^{+}$; found: 373.2271; IR $\left(\mathrm{KBr}, \mathrm{cm}^{-1}\right)$ : 1591.3, 1475.5, 1444.7, 1421.5, 1392.6, 1375.3, $1303.9,1253.7,1205.5,1103.3,1074.4,1033.9,1016.5,954.8,939.3$.

Reaction of 4 with MeOTf. MeOTf $(7.42 \mu \mathrm{l}, 0.068 \mathrm{mmol})$ was added into an acetonitrile $(6 \mathrm{ml})$ solution of $4(0.021 \mathrm{~g}, 0.056 \mathrm{mmol})$ and stirred for $1 \mathrm{~h}$ at room temperature. After the solvent was removed under vacuum, the solid residue was recrystallized from a 2:1 mixture of fluorobenzene/hexane to afford colourless crystals of $5(0.022 \mathrm{~g}, 75 \%)$. Mp: $151{ }^{\circ} \mathrm{C}(\mathrm{dec}) .{ }^{1} \mathrm{H}$ NMR $\left(400 \mathrm{MHz}\right.$, THF- $\left.\mathrm{d}_{8}\right)$ : $\delta=0.34(\mathrm{~s}, 3 \mathrm{H}), 0.87(\mathrm{~s}, 6 \mathrm{H}), 1.38(\mathrm{~s}, 6 \mathrm{H}), 4.14(\mathrm{~d}, 2 \mathrm{H}, J=8.8 \mathrm{~Hz}), 4.26(\mathrm{~d}, 2 \mathrm{H}$, $J=8.4 \mathrm{~Hz}), 7.06-7.66(\mathrm{~m}, 10 \mathrm{H}) ;{ }^{13} \mathrm{C}$ NMR $\left(100 \mathrm{MHz}, \mathrm{THF}-\mathrm{d}_{8}\right): \delta=22.4,29.0$, 67.3, 83.2, 126.1, 127.7, 128.1, 129.6, 130.8, 132.4; ${ }^{11} \mathrm{~B}$ NMR (76.8 MHz, THF- $\left.\mathrm{d}_{8}\right)$ : $\delta=-19.7$ (s), $4.2(\mathrm{~s}) ;{ }^{19} \mathrm{~F}$ NMR (225.6 MHz, THF- $\left.\mathrm{d}_{8}\right): \delta=-81.2$; HRMS (ESI): $m / z$ calculated for $\mathrm{C}_{24} \mathrm{H}_{30} \mathrm{~B}_{2} \mathrm{~N}_{2} \mathrm{O}_{5} \mathrm{SF}_{3}: 537.2014[(M+H)]^{+}$; found: 537.2006 .

Reaction of 4 with phenylacetylene. Phenylacetylene $(9.2 \mu \mathrm{l}, 0.087 \mathrm{mmol})$ was added into a $\mathrm{C}_{6} \mathrm{D}_{6}(0.5 \mathrm{ml})$ solution of $4(0.031 \mathrm{~g}, 0.083 \mathrm{mmol})$ and heated at $70^{\circ} \mathrm{C}$. Reaction was monitored by NMR spectroscopy. After $2 \mathrm{~h}$, the solvent was removed under vacuum, and the solid residue was recrystallized from THF/hexane to afford colourless crystals of $6(0.036 \mathrm{~g}, 91 \%)$. Mp: $120{ }^{\circ} \mathrm{C} .{ }^{1} \mathrm{H}$ NMR $\left(400 \mathrm{MHz}, \mathrm{C}_{6} \mathrm{D}_{6}\right)$ : $\delta=0.52(\mathrm{~s}, 6 \mathrm{H}), 0.87(\mathrm{~s}, 6 \mathrm{H}), 3.44(\mathrm{~d}, 2 \mathrm{H}, J=8.4 \mathrm{~Hz}), 3.51(\mathrm{~d}, 2 \mathrm{H}, J=8.4 \mathrm{~Hz})$, $7.01-8.04(\mathrm{~m}, 16 \mathrm{H}) ;{ }^{13} \mathrm{C}$ NMR $\left(125 \mathrm{MHz}, \mathrm{CDCl}_{3}\right): \delta=25.0,27.4,65.9,84.9,124.7$, $125.3,126.7,127.2,127.6,127.9,128.5,132.3,135.2 ;{ }^{11} \mathrm{~B}$ NMR $\left(76.8 \mathrm{MHz}, \mathrm{C}_{6} \mathrm{D}_{6}\right)$ : $\delta=-13.6(\mathrm{~s}), 0.1(\mathrm{~s})$; HRMS (ESI): $\mathrm{m} / z$ calculated for $\mathrm{C}_{30} \mathrm{H}_{33} \mathrm{~B}_{2} \mathrm{~N}_{2} \mathrm{O}_{2}: 475.2728$ $[(M+H)]^{+}$; found: 475.2733 .

Reaction of 4 with $\mathbf{C O}_{2}$. A benzene $(15 \mathrm{ml})$ solution of compound $4(0.061 \mathrm{~g}$, $0.040 \mathrm{mmol}$ ) was degassed using a freeze-pump-thaw method, and then $\mathrm{CO}_{2}(1 \mathrm{bar})$ was introduced into the schlenk tube at room temperature. After $2 \mathrm{~h}$ at $70^{\circ} \mathrm{C}$, a white precipitate was collected by filtration and dried under vacuum to afford $7(0.049 \mathrm{~g}$, $72 \%)$. Mp: $158^{\circ} \mathrm{C}(\mathrm{dec}) .{ }^{1} \mathrm{H}$ NMR $\left(400 \mathrm{MHz}, \mathrm{CD}_{2} \mathrm{Cl}_{2}\right): \delta=0.90(\mathrm{~s}, 6 \mathrm{H}), 1.50(\mathrm{~s}, 6$ $\mathrm{H}), 4.36(\mathrm{~d}, 2 \mathrm{H}, J=9.2 \mathrm{~Hz}), 4.39(\mathrm{~d}, 2 \mathrm{H}, J=9.2 \mathrm{~Hz}), 7.22-7.95(\mathrm{~m}, 10 \mathrm{H}) ;{ }^{13} \mathrm{C} \mathrm{NMR}$ $\left(100 \mathrm{MHz}, \mathrm{CD}_{2} \mathrm{Cl}_{2}\right): \delta=25.9,27.7,66.5,86.4,126.9,127.5,129.1,134.97,134.99$, 135.1; ${ }^{11} \mathrm{~B}$ NMR (76.8 MHz, $\mathrm{CD}_{2} \mathrm{Cl}_{2}$ ): $\delta=-16.7$ (s), 3.1 (s); HRMS (ESI): $m / z$ calculated for $\mathrm{C}_{23} \mathrm{H}_{27} \mathrm{~B}_{2} \mathrm{~N}_{2} \mathrm{O}_{4}: 417.2157[(M+H)]^{+}$; found: 417.2161 .

Reaction of 4 with ${ }^{13} \mathrm{CO}_{2}$. Compound $\mathbf{4}(0.015 \mathrm{~g}, 0.040 \mathrm{mmol})$ was added to a sealable J-Young NMR tube and was dissolved in $\mathrm{C}_{6} \mathrm{D}_{6}(0.35 \mathrm{ml})$. The sample was degassed using a freeze-pump-thaw method. Labile ${ }^{13} \mathrm{CO}_{2}$ was condensed into the NMR tube at $77 \mathrm{~K}$, followed by warming to room temperature, and reacted for $2 \mathrm{~h}$ at $70^{\circ} \mathrm{C}$. A white precipitate was collected by filtration and dried under vacuum to afford ${ }^{7}-{ }^{13} \mathrm{C}(0.013 \mathrm{~g}, 80 \%$ yield $) .{ }^{13} \mathrm{C}$ NMR $\left(100 \mathrm{MHz}, \mathrm{CD}_{2} \mathrm{Cl}_{2}\right): \delta=25.9,27.7$, $66.5,86.4,126.9,127.5,129.1,134.97,134.99,135.1,191.1\left(\mathrm{br} \mathrm{d}, J_{\mathrm{CB}}=42.4 \mathrm{~Hz}\right) ;{ }^{11} \mathrm{~B}$ NMR $\left(76.8 \mathrm{MHz}, \mathrm{CD}_{2} \mathrm{Cl}_{2}\right): \delta=-16.7\left(\mathrm{br} \mathrm{d}, J_{\mathrm{BC}}=42.4 \mathrm{~Hz}\right), 3.1(\mathrm{~s})$.

Regeneration of 4 from 7. Compound 7 was dissolved in a 1:1 mixture of $\mathrm{CD}_{3} \mathrm{CN} / \mathrm{THF}-\mathrm{d}_{8}$ and heated at $90^{\circ} \mathrm{C}$. Reaction was monitored by ${ }^{1} \mathrm{H}$ and ${ }^{11} \mathrm{~B}$
NMR spectroscopy and after $50 \mathrm{~min}$, a quantitative regeneration of $\mathbf{4}$ was confirmed.

\section{References}

1. Kekulé, A. Sur la constitution des substances aromatiques. Bull. Soc. Chim. Fr 3, 98-110 (1865)

2. Faraday, M. On new compounds of carbon and hydrogen, and on certain other products obtained during the decomposition of oil by heat. Phil. Trans. R. Soc. Lond. 115, 440-466 (1825).

3. Stock, A. \& Pohland, E. Borwasserstoffe, IX.: $\mathrm{B}_{3} \mathrm{~N}_{3} \mathrm{H}_{6}$. Ber. Dtsch. Chem. Ges. A/ B 59, 2215-2223 (1926).

4. Bean, D. E. \& Fowler, P. W. Effect on ring current of the Kekule vibration in aromatic and antiaromatic rings. J. Phys. Chem. A 115, 13649-13656 (2011).

5. Phukan, A. K., Guha, A. K. \& Silvi, B. Is delocalization a prerequisite for stability of ring systems? A case study of some inorganic rings. Dalton Trans. 39, 4126-4137 (2010).

6. Liu, Z. \& Marder, T. B. B-N versus C-C: how similar are they? Angew. Chem Int. Ed. 47, 242-244 (2008).

7. Bosdet, M. J. D. \& Piers, W. E. B-N as a C-C substitute in aromatic systems. Can. J. Chem. 87, 8-29 (2009).

8. Ashe, III A. J. Aromatic borataheterocycles: surrogates for cyclopentadienyl in transition-metal complexes. Organometallics 28, 4236-4248 (2009).

9. Dewar, M. J. S., Kubba, V. P. \& Pettit, R. New heteroaromatic compounds. Part I. 9-Aza-10-boraphenanthrene. J. Chem. Soc. 3073-3076 (1958).

10. Campbell, P. G., Marwitz, A. J. V. \& Liu, S.-Y. Recent advances in azaborine chemistry. Angew. Chem. Int. Ed. 51, 6074-6092 (2012).

11. Jaska, C. A. et al. Triphenylene analogues with $\mathrm{B}_{2} \mathrm{~N}_{2} \mathrm{C}_{2}$ cores: synthesis, structure, redox behavior, and photophysical properties. J. Am. Chem. Soc. 128, 10885-10896 (2006).

12. Forster, T. D. et al. A $\sigma$-donor with a planar six- $\pi$-electron $\mathrm{B}_{2} \mathrm{~N}_{2} \mathrm{C}_{2}$ framework: anionic N-heterocyclic carbene or heterocyclic terphenyl anion? Angew. Chem. Int. Ed. 45, 6356-6359 (2006).

13. Kinjo, R., Donnadieu, B., Celik, M. A., Frenking, G. \& Bertrand, G. Synthesis and characterization of a neutral tricoordinate organoboron isoelectronic with amines. Science 333, 610-613 (2011).

14. Kong, L., Li, Y., Ganguly, R., Vidovic, D. \& Kinjo, R. Isolation of a bis(oxazol-2ylidene)-phenylborylene adduct and its reactivity as a boron-centered nucleophile. Angew. Chem. Int. Ed. 53, 9280-9283 (2014).

15. Ruiz, D. A., Melaimi, M. \& Bertrand, G. An efficient synthetic route to stable bis(carbene)borylenes $\left[\left(\mathrm{L}_{1}\right)\left(\mathrm{L}_{2}\right) \mathrm{BH}\right.$. Chem. Commun. 50, 7837-7839 (2014).

16. Kong, L., Ganguly, R., Li, Y. \& Kinjo, R. Diverse reactivity of a tricoordinate organoboron $\mathrm{L}_{2} \mathrm{PhB}$ : ( $\mathrm{L}=$ oxazol-2-ylidene) towards alkali metal, group 9 metal, and coinage metal precursors. Chem. Sci. 6, 2893-2902 (2015).

17. Creutz, C. \& Taube, H. Direct approach to measuring the Franck-Condon barrier to electron transfer between metal ions. J. Am. Chem. Soc. 91, 3988-3989 (1969).

18. Creutz, C. \& Taube, H. Binuclear complexes of ruthenium ammines. J. Am. Chem. Soc. 95, 1086-1094 (1973).

19. Robin, M. B. \& Day, P. Mixed-valence chemistry: a survey and classification. Adv. Inorg. Chem. Radiochem 10, 247-422 (1967).

20. Aguirre-Etcheverry, P. \& O'Hare, D. Electronic communication through unsaturated hydrocarbon bridges in homobimetallic organometallic complexes. Chem. Rev. 110, 4839-4864 (2010).

21. Hankache, J. \& Wenger, O. S. Organic mixed valence. Chem. Rev. 111, 5138-5178 (2011).

22. Abe, M. Diradicals. Chem. Rev. 113, 7011-7088 (2013).

23. Heckmann, A. \& Lambert, C. Organic mixed-valence compounds: a playground for electrons and holes. Angew. Chem. Int. Ed. 51, 326-392 (2012).

24. Low, P. J. Twists and turns: studies of the complexes and properties of bimetallic complexes featuring phenylene ethynylene and related bridging ligands. Coord. Chem. Rev. 257, 1507-1532 (2013).

25. Parthey, M. \& Kaupp, M. Quantum-chemical insights into mixed-valence systems: within and beyond the Robin-Day scheme. Chem. Soc. Rev. 43, 5067-5088 (2014).

26. Abersfelder, K., White, A. J. P., Rzepa, H. S. \& Scheschkewitz, D. A tricyclic aromatic isomer of hexasilabenzene. Science 327, 564-566 (2010)

27. Canac, Y. et al. Isolation of a benzene valence isomer with one-electron phosphorus-phosphorus bonds. Science 279, 2080-2082 (1998).

28. Pistolis, G. Dual excimer emission of p-terphenyl induced by $\gamma$-cyclodextrin in aqueous solutions. Chem. Phys. Lett. 304, 371-377 (1999).

29. Hong, Y., Lam, J. W. Y. \& Tang, B. Z. Aggregation-induced emission. Chem. Soc. Rev. 40, 5361-5388 (2011).

30. Hong, Y., Lam, J. W. Y. \& Tang, B. Z. Aggregation-induced emission: phenomenon, mechanism and applications. Chem. Commun. 45, 4332-4353 (2009).

31. Xu, S., Mikulas, T. C., Zakharov, L. N., Dixon, D. A. \& Liu, S.-Y. Boronsubstituted 1,3-dihydro-1,3-azaborines: synthesis, structure, and evaluation of aromaticity. Angew. Chem. Int. Ed. 52, 7527-7531 (2013). 
32. Marwitz, A. J. V., Matus, M. H., Zakharov, L. N., Dixon, D. A. \& Liu, S.-Y. A hybrid organic/inorganic benzene. Angew. Chem. Int. Ed. 48, 973-977 (2009).

33. Stephan, D. W. \& Erker, G. Frustrated Lewis pairs: metal-free hydrogen activation and more. Angew. Chem. Int. Ed. 49, 46-76 (2010)

34. Power, P. P. Main-group elements as transition metals. Nature 463, 171-177 (2010).

35. Yao, S., Xiong, Y. \& Driess, M. Zwitterionic and donor-stabilized $\mathrm{N}$-heterocyclic silylenes (NHSis) for metal-free activation of small molecules Organometallics 30, 1748-1767 (2011).

36. Mandal, S. K. \& Roesky, H. W. Group 14 hydrides with low valent elements for activation of small molecules. Acc. Chem. Res. 45, 298-307 (2012).

37. Stephan, D. W. Frustrated Lewis pairs: from concept to catalysis. Acc. Chem Res. 48, 306-316 (2015)

38. Krespan, C. G., McKusick, B. C. \& Cairns, T. L. Bis-(polyfluoroalkyl)acetylenes. II. Bicycloöctatrienes through 1,4-addition of bis-(polyfluoroalkyl)acetylenes to aromatic rings. J. Am. Chem. Soc. 83, 3428-3432 (1961).

39. Zimmerman, H. E., Grunewald, G. L., Paufler, R. M. \& Sherwin, M. A Synthesis and physical properties of barrelene, a unique Moebius-like molecule. J. Am. Chem. Soc. 91, 2330-2338 (1969).

40. Stephan, D. W. \& Erker, G. Frustrated Lewis pair chemistry of carbon, nitrogen and sulfur oxides. Chem. Sci. 5, 2625-2641 (2014).

41. Olah, G. A. et al. Efficient chemoselective carboxylation of aromatics to arylcarboxylic acids with a superelectrophilically activated carbon dioxide $-\mathrm{Al}_{2} \mathrm{Cl}_{6} / \mathrm{Al}$ System. J. Am. Chem. Soc. 124, 11379-11391 (2002).

\section{Acknowledgements}

We gratefully acknowledge financial support from Nanyang Technological University (NTU; Singapore) and A*STAR (Agency for Science, Technology and Research, PSF/ SERC 1321202066) of Singapore. We also thank Yanli Zhao and Pengyao Xing (NTU) for their assistance in fluorescence spectra analysis.

\section{Author contributions}

D.W. performed most of the synthetic experiments. L.K. conducted part of the syntheses and spectroscopic characterizations. Y.L. and R.G. performed the X-ray crystallographic measurements. R.K. conceived and supervised the study, and drafted the manuscript with the assistance from L.K.. All authors contributed to discussions.

\section{Additional information}

Accession codes: The X-ray crystallographic coordinates for structures reported in this article have been deposited at the Cambridge Crystallographic Data Centre (CCDC) under deposition numbers CCDC 1049275-1049279. These data can be obtained free of charge from The Cambridge Crystallographic Data Centre via www.ccdc.cam.ac.uk/ data_request/cif.

Supplementary Information accompanies this paper at http://www.nature.com/ naturecommunications

Competing financial interests: The authors declare no competing financial interests

Reprints and permission information is available online at http://npg.nature.com/ reprintsandpermissions/

How to cite this article: Wu, D. et al. 1,3,2,5-Diazadiborinine featuring nucleophilic and electrophilic boron centres. Nat. Commun. 6:7340 doi: 10.1038/ncomms8340 (2015).

(c) (i) This work is licensed under a Creative Commons Attribution 4.0 International License. The images or other third party material in this article are included in the article's Creative Commons license, unless indicated otherwise in the credit line; if the material is not included under the Creative Commons license, users will need to obtain permission from the license holder to reproduce the material. To view a copy of this license, visit http://creativecommons.org/licenses/by/4.0/ 